\title{
Effect of Olmesartan-Based Therapies on Therapeutic Indicators Obtained Through Out-of-Office Blood Pressure
}

Manuel Gorostidi

To view enhanced content go to www.cardiologytherapy-open.com

Received: April 13, 2015 / Published online: June 13, 2015

(c) The Author(s) 2015. This article is published with open access at Springerlink.com

\section{ABSTRACT}

Ambulatory blood pressure (BP) correlates more significantly with hypertension-associated cardiovascular mortality and morbidity than BP obtained in the doctor's office. Assessing ambulatory BP, either through 24-h monitoring or through protocolized self-measurement at home, is essential in diagnosing and monitoring patients with hypertension. Several ambulatory BP-derived indicators are related with cardiovascular prognosis. These include 24-h, daytime and nighttime BP measurements, BP measurements obtained through home self-measurement, dipping status, morning surge, and BP variability. The objective of this article was to review the effect of olmesartan-based antihypertensive therapy on the main risk variables obtained when assessing ambulatory BP.

Electronic supplementary material The online version of this article (doi:10.1007/s40119-015-0042-2) contains supplementary material, which is available to authorized users.

M. Gorostidi $(\bowtie)$

Nephrology Department, Hospital Universitario Central de Asturias, RedinRen, Oviedo, Asturias, Spain

e-mail: manuel.gorostidi@gmail.com
Keywords: Ambulatory blood pressure monitoring; Ambulatory blood pressure; Blood pressure; Home blood pressure monitoring; Hypertension; Olmesartan

\section{INTRODUCTION}

Hypertension (HTN) is a key factor in the development of cardiovascular disease. The increase in blood pressure (BP) from optimal levels correlates with coronary heart disease, stroke, heart failure, sudden death, chronic kidney disease, and peripheral arterial disease, which are the leading causes of disease and death in the world. HTN affects $30-40 \%$ of the adult population. In addition, BP increases with age so that the prevalence of HTN in the elderly is over 50\% [1-3]. In Spain, 33\% of adults are hypertensive and the prevalence of HTN in the population over 60 years of age is close to $70 \%$ [4]. Antihypertensive treatment is considered to be one of the main achievements in medicine in recent decades, since reducing high $\mathrm{BP}$ significantly reduces HTN-related morbidity and mortality [5].

Most of the basic concepts regarding HTN are based on the classical measurement of BP in the 
doctor's office. However, the main limitation of this method is that it only offers a momentary $\mathrm{BP}$ value that, in addition, is subject to factors that may occasionally change it [6-8]. To optimize assessing true BP values, techniques have been developed to self-measure $\mathrm{BP}$ at home, also called home BP monitoring (HBPM) and automated BP measurement over $24 \mathrm{~h}$ or ambulatory BP monitoring (ABPM). The BP levels obtained using HBPM [9-14] and those recorded using ABPM [11, 15-21] are more closely correlated with target organ damage and cardiovascular disease than the BP levels obtained in the doctor's office. Ambulatory BP measurement is currently considered a basic indication for diagnosing and monitoring patients with HTN [1, 22].

The objective of this article was to review the studies on the effect of olmesartan-based antihypertensive therapies on the main prognostic indicators related to ambulatory BP.

\section{METHODS}

Olmesartan was chosen to perform this review because recent studies analyzing the abovementioned variables have been developed using this drug. A PubMed search was conducted combining the terms 'olmesartan', 'olmesartan and hydrochlorothiazide', 'olmesartan and amlodipine', 'olmesartan and hydrochlorothiazide and amlodipine', 'home blood pressure measurement', and 'ambulatory blood pressure monitoring'. Furthermore, additional searches were conducted using the terms pertaining to treatments, and 'blood pressure control', 'ambulatory blood pressure control', 'morning surge', 'blood pressure variability', and 'chronotherapy', selecting the studies according to the review objective.
This article is based on previously conducted studies and does not involve any new studies of human or animal subjects performed by the author.

\section{CURRENT INDICATIONS FOR AMBULATORY BP MEASUREMENT}

As mentioned previously, measuring ambulatory BP is currently considered a basic examination in diagnosing $\mathrm{HTN}$ and in assessing the degree of BP control. The recommendations from the British National Institute for Health and Clinical Excellence guidelines establish that either ABPM or HBPM be performed to confirm the HTN diagnosis [22]. The current guidelines from the European Societies of Hypertension and Cardiology define HTN both with the classic in-office figures as well as with ambulatory BP levels [1]. Moreover, ambulatory BP measurement improves the assessment of patients with HTN by determining a series of additional indicators. The current ABPM and HBPM indications from the European Societies of Hypertension and Cardiology are listed in Table 1.

\section{AMBULATORY BP CONTROL MEASURED WITH ABPM}

The assessment of ambulatory BP over a 24-h period and the corresponding daytime and nighttime periods is probably the main input for ABPM. As for treated patients, ABPM enables discerning between proper HTN control over $24 \mathrm{~h}$ and a lack of true control, not just while at the doctor's office. It is a well-known fact that most patients with HTN need combined treatment with two or more antihypertensive drugs to achieve adequate control, and that 
Table 1 Indications for measuring ambulatory blood pressure according to the current guidelines from the European Societies of Hypertension and Cardiology

Indications for HBPM or ABPM

Suspicion of white-coat HTN

Grade I HTN in the office

HTN in individuals without asymptomatic organ damage and at low total CV risk

Suspicion of masked HTN

High normal BP in the office

Normal office BP in individuals with asymptomatic organ damage

Normal office BP in individuals with high total CV risk

Identification of white-coat effect in patients with HTN

Considerable variability of in-office BP during a single visit

Considerable variability of in-office BP over different visits

Suspicion of autonomic, postural, postprandial, siesta- and drug-induced hypotension

HTN or suspected pre-eclampsia in pregnant women

Identification of true and false resistant HTN

Specific indications for ABPM

Marked discordance between in-office BP and home BP

Assessment of dipping status

Suspicion of nighttime HTN or absence of dipping, such as in patients with sleep apnea, chronic kidney disease, or diabetes

Assessment of BP variability

$A B P M$ Ambulatory blood pressure monitoring, $B P$ blood pressure, $C V$ cardiovascular, $H B P M$ home blood pressure monitoring, HTN hypertension

Information from Ref. [1]

probably $15-20 \%$ of patients need at least three antihypertensive drugs [1]. In the analyses of a national ABPM registry (Spanish ABPM Registry), it has been observed that using a combined antihypertensive treatment is common, especially in cases with high cardiovascular risk, but the ambulatory BP control rate does not reach 50\% [23-25]. The data corresponding to the different hypertensive subgroups are presented in Table 2. In low-to-moderate-risk patients without diabetes or kidney disease, a relatively low use of combined treatments was observed, being control rates less than 50\%. This figure was probably an expression of therapeutic inertia or nihilism. In higher-risk patients, with diabetes or kidney disease, the therapeutic effort was higher but the control rates were even more unfavorable.

Using combined antihypertensive treatment earlier and a more systematic indication for triple therapy when control is not achieved 
Table 2 Prevalence of uncontrolled ambulatory blood pressure in different hypertensive subgroups and usage rates of combination antihypertensive therapies: Data from the Spanish ABPM Registry

Gorostidi et al. [23]: comparison between high-risk and low/moderate-risk subjects with HTN

\begin{tabular}{lll}
\hline & High-risk & Low/moderate-risk \\
\hline$N$ & 6534 & 10,685 \\
Combination of 2 drugs (\%) & 27.2 & 19.6 \\
Combination of 3 or more drugs (\%) & 31.4 & 13.3 \\
24-h BP $\geq 130 / 80 \mathrm{mmHg}(\%)$ & 76.3 & 63.9 \\
\hline
\end{tabular}

Gorostidi et al. [24]: comparison between hypertensive subjects with and without diabetes

\begin{tabular}{lll}
\hline & With diabetes & Without diabetes \\
\hline$N$ & 12,600 & 55,445 \\
Combination of 2 drugs & 25.1 & 20.2 \\
Combination of 3 or more drugs & 33.8 & 17.0 \\
$24-\mathrm{h} \mathrm{BP} \geq 130 / 80 \mathrm{mmHg}$ & 59.3 & 55.4 \\
\hline
\end{tabular}

Gorostidi et al. [25]: comparison between hypertensive subjects with and without kidney disease

\begin{tabular}{lll}
\hline & With kidney disease & Without kidney disease \\
\hline$N$ & 5693 & 8689 \\
Combination of 2 drugs (\%) & 25.9 & 21.6 \\
Combination of 3 or more drugs (\%) & 40.2 & 20.4 \\
$24-\mathrm{h} \mathrm{BP} \geq 130 / 80 \mathrm{mmHg}(\%)$ & 56.5 & 53.8 \\
\hline
\end{tabular}

$A B P M$ ambulatory blood pressure monitoring, $B P$ blood pressure, $H T N$ hypertension

with two drugs might result in improvements in control rates. The most appropriate triple combination has been considered to be one that includes a renin-angiotensin system blocker, a calcium-channel blocker, and a diuretic [1]. As for olmesartan-based combinations, two studies have assessed the degree of control reached in ambulatory BP. In a sub-analysis of the TRINITY trial (Triple therapy with olmesartan medoxomil, amlodipine, and hydrochlorothiazide in hypertensive patients; ClinicalTrials.gov number, NCT00649389) the effect of triple combination therapy was assessed, with doses up to $40 \mathrm{mg}$ of olmesartan, $10 \mathrm{mg}$ of amlodipine, and $25 \mathrm{mg}$ of hydrochlorothiazide, using ABPM in 440 patients with HTN defined as moderate to severe based on a systolic BP $\geq 160 \mathrm{mmHg}$ or a diastolic BP $\geq 100 \mathrm{mmHg}$. After a 12-week treatment period, $86.5 \%$ of patients presented a mean $24-\mathrm{h} \mathrm{BP}<130 / 80 \mathrm{mmHg}, 79.8 \%$ a mean daytime $\mathrm{BP}<135 / 85 \mathrm{mmHg}$, and also $79.8 \%$ a mean nighttime $\mathrm{BP}<120 / 80 \mathrm{mmHg}$ [26].

In another sub-analysis, in this case the BPCRUSH study (Blood pressure control in all subgroups with hypertension; ClinicalTrials.gov number, NCT00791258), with a similar design to the previous one and including 243 patients, the degree of ambulatory BP control obtained with the full doses of olmesartan, amlodipine, 
and hydrochlorothiazide was $90.5 \%$ for mean 24-h BP, $88.4 \%$ for daytime BP, and $78.9 \%$ for mean nighttime BP, defined as a BP $<120$ / $70 \mathrm{mmHg}$ [27]. The characteristics and the basic results of these studies are presented in Table 3.

Logically, in other trials with double combinations of olmesartan and hydrochlorothiazide and of olmesartan and amlodipine, the ambulatory BP control rates were lower although more favorable than those observed in daily practice. In the REZALT study (Efficacy and tolerability of olmesartan medoxomil and azelnidipine combination therapy compared with monotherapy with each agent in Japanese patients with essential hypertension; Japan Pharmaceutical Information Center registration number, JapicCTI-060286), the combination treatment with olmesartan and azelnidipine resulted in a greater decrease in ambulatory BP than with the corresponding monotherapies $[28,29]$. In the AZTEC study (AZOR trial evaluating blood pressure reductions and control), with 290 subjects with HTN, $70.9 \%$ reached a mean 24-h ambulatory $\mathrm{BP}<130 / 80 \mathrm{mmHg}$ with the combination of olmesartan $40 \mathrm{mg}$ and amlodipine $10 \mathrm{mg}$ [30].

In the APEX study (Ambulatory BP monitoring study to evaluate the safety and efficacy of an olmesartan medoxomil- and amlodipine-based treatment regimen in patients with type 2 diabetes and hypertension), 207 patients with type 2 diabetes and HTN received a treatment titrated until reaching the full dose of olmesartan and amlodipine, and $70 \%$ of patients reached a mean 24-h daytime BP $<130 / 80 \mathrm{mmHg}$ [31]. The SEVICONTROL-1 (Daytime systolic ambulatory blood pressure with a direct switch between candesartan monotherapy and the fixed-dose combination olmesartan/ amlodipine in patients with uncontrolled essential hypertension; ClinicalTrials.gov number, NCT01613209) and SEVICONTROL-2 (Efficacy and safety of a therapy change from candesartan $32 \mathrm{mg}$ to fixed combination of olmesartan $\quad 40 \mathrm{mg} /$ amlodipine $10 \mathrm{mg}$; ClinicalTrials.gov number, NCT01611077)

Table 3 Degree of ambulatory blood pressure control assessed using ambulatory blood pressure monitoring, in studies with olmesartan-based triple combination

\begin{tabular}{|c|c|c|c|c|}
\hline Study & $N$ & Patients and methods & Duration & Main outcomes ${ }^{\mathbf{a}}$ \\
\hline $\begin{array}{l}\text { Izzo } \\
\text { et al. } \\
{[26]}\end{array}$ & 440 & $\begin{array}{l}\text { Sub-analysis of the TRINITY study. Patients } \\
\text { with moderate or severe HTN (systolic BP } \\
\geq 160 \mathrm{mmHg} \text { or diastolic BP } \geq 100 \mathrm{mmHg} \text { ) } \\
\text { treated with OLM/AML/HCT up to } 40 / 10 \text { / } \\
25 \mathrm{mg}\end{array}$ & 12 weeks & $\begin{array}{l}\text { 24-h BP <130/80 mmHg, } 86.5 \% \text {; daytime } \\
\text { BP < }<135 / 85 \mathrm{mmHg}, 79.8 \% \text {; nighttime BP } \\
\quad<120 / 80 \mathrm{mmHg}, 79.8 \%\end{array}$ \\
\hline $\begin{array}{l}\text { Weir } \\
\text { et al. } \\
{[27]}\end{array}$ & 243 & $\begin{array}{l}\text { Sub-analysis of BP-CRUSH study. Uncontrolled } \\
\text { patients with treated with monotherapy OLM/ } \\
\text { AML/HCT up to } 40 / 10 / 25 \mathrm{mg}\end{array}$ & 20 weeks & $\begin{array}{l}\text { 24-h } \mathrm{BP}<130 / 80 \mathrm{mmHg}, 90.5 \% \text {; daytime } \\
\text { BP }<135 / 85 \mathrm{mmHg}, 88.4 \% \text {; nighttime BP } \\
\quad<120 / 70 \mathrm{mmHg}, 78.9 \%\end{array}$ \\
\hline
\end{tabular}

$A M L$ amlodipine, BP blood pressure, BP-CRUSH blood pressure control in all subgroups with hypertension, $H C T$ hydrochlorothiazide, HTN hypertension, OLM olmesartan, TRINITY triple therapy with olmesartan medoxomil, amlodipine, and hydrochlorothiazide in hypertensive patients study

a Outcomes obtained with the complete doses 
studies, in which 78 and 77 patients, respectively, who were uncontrolled with $32 \mathrm{mg}$ of candesartan, substituted this treatment with the combination of olmesartan $40 \mathrm{mg}$ and amlodipine $10 \mathrm{mg}$, directly in the SEVICONTROL-1 study and sequentially in the SEVICONTROL-2 study. The daytime ambulatory BP control rates (mean daytime BP $<135 / 85 \mathrm{mmHg}$ ) in 12 weeks of treatment were $77.6 \%$ and $78.4 \%$, respectively $[32,33]$.

The fact that the study protocols include strict guidelines on increasing the dose or combining drugs if the clinical BP is not controlled, compared with a possible inertia in routine clinical practice, is one of the factors usually invoked to explain the differences in control rates obtained in clinical trials compared with those observed in care surveys [34].

\section{AMBULATORY BP CONTROL MEASURED WITH HBPM}

As mentioned in the introduction, home BP measurements are more useful than in-office measurements for HTN diagnosis, for predicting cardiovascular events and for assessing treatment efficacy. One study, called HONEST (Home blood pressure measurement with olmesartan naive patients to establish standard target blood pressure; Trial registration number, UMIN000002567), with olmesartan-based treatment, was specifically designed to assess the relationships between HBPM with the effects of the therapy. HONEST observed the relationships between the home measurement, clinic measurement, and the incidence of cardiovascular events in 22,373 patients receiving olmesartan-based antihypertensive treatment. Most studies about the relationships between home BP measurements and cardiovascular prognosis are observations based on initial measurements. The HONEST study will provide data on the prognostic value of home measurements taken during follow-up [35]. In the first publication of results, regarding the short-term efficacy of the olmesartan-based treatment guidelines, it was reported that the percentage of patients who achieved adequate control of clinic systolic BP (systolic BP $<140 \mathrm{mmHg}$ ) and home systolic BP (systolic BP $<135 \mathrm{mmHg}$ ), simultaneously, increased from $7.9 \%$ to $38.9 \%$ after 16 weeks of followup [36].

\section{CIRCADIAN RHYTHM AND CHRONOTHERAPY}

The relationship between absolute ambulatory BP levels and cardiovascular morbidity and mortality is well established. Of the different periods typically analyzed ( $24 \mathrm{~h}$, day and night), nighttime $\mathrm{BP}$ is the variable that is best correlated with the prognosis. In addition, the relationship between daytime BP and nighttime BP (circadian profile) also predicts HTN-related asymptomatic target organ damage and cardiovascular events $[1,8,18,19,21,37]$. Changes in the normal circadian profile (nondipper pattern) are very common in hypertensive patients, affecting approximately $50 \%$ of cases [38]. There is a close relationship between the non-dipper profile and cardiovascular risk such that in patients at high risk in general or in patients with diabetes and HTN, the prevalence of this change can reach $60 \%[23,24]$.

Chronotherapy in HTN, or administering the hypertensive treatment at a certain time of day, proposes that taking the medication at night has an added beneficial effect on the normal decrease in BP by exercising a favorable action 
on the circadian profile with outcomes that even improve morbidity and mortality [39]. However, this therapeutic approach is under debate, as the results of other studies do not corroborate these findings [40]. Regarding olmesartan-based studies, in some, nighttime administration of the drug has been described to result in an added beneficial effect [41, 42] whereas others have not reproduced these results [43, 44]. In the COMPATIBLE study (Comparison of effects of angiotensin II receptor blocker on morning home blood pressure and cardiorenal protection between morning administration and evening administration in hypertensive patients; Trial registration number, UMIN000003238), 218 patients were randomized to take olmesartan in the morning or at night and the reductions in clinic BP, morning home BP, urinary excretion of albumin, and electrocardiographic parameters of left ventricular hypertrophy were similar in patients who received the treatment in the morning or at night [43].

\section{MORNING SURGE IN BP}

The increase in BP that is observed when waking and especially when starting daily activity is considered a physiological process. However, there is a controversy about whether or not an excessive morning BP surge may cause a negative prognosis [8]. In this sense, it has been recognized that the antihypertensive treatment that minimizes the morning $\mathrm{BP}$ surge, without causing excessive reductions over the rest of the day, has an added beneficial effect.

One of the most studied related variables is the trough-to-peak ratio, considering the peak time as the 2 consecutive hours with the largest reduction in BP in the period between 2 and $8 \mathrm{~h}$ after taking the treatment and the trough time 23 and $24 \mathrm{~h}$ after taking the treatment, considering ideal the best proximity to the unit that reflects a homogeneous effect over $24 \mathrm{~h}$. Two recent studies with olmesartan-based treatment have measured this variable. Both in the EXPO study [45, 46] and in Bilo et al. [47], the treatment caused a lasting effect over the 24-h period, with a trough-to-peak ratio greater than 0.6. In the Bilo et al. [47] study, which also assesses this parameter with the olmesartan and amlodipine combinations, a more favorable trough-to-peak ratio was observed in patients who received the combination. Use of longacting antihypertensive drugs should be of key importance for adequate BP morning surge control. As shown in a recent meta-analysis, losartan was less effective than other angiotensin receptor blockers for controlling 24-h BP [48].

\section{BP VARIABILITY}

Although the cardiovascular complications of HTN are essentially related to the absolute BP levels, increased BP variability may have an added deleterious effect. Thus, relationships between cardiovascular morbidity/mortality and very-short-term variability (beat to beat), short term (in a 24-h period), long term (between days), and very long term (between doctor's visits) have been described $[49,50]$.

There is a close relationship between elevated BP levels, a higher cardiovascular risk, and an increased variability in BP assessed using ABPM [23]. In most of the studies mentioned so far that have assessed this indicator, a reduction in BP variability related to the reduction in absolute BP levels caused by the various treatments was observed. Thus, certain results are of additional interest. In a post hoc analysis 
of Japan combined treatment with olmesartan and a calcium-channel blocker versus olmesartan and diuretics randomized efficacy study, in which the patients initially treated with olmesartan were randomized to receive additional treatment with azelnidipine or with hydrochlorothiazide, the patients treated with olmesartan and the calcium-channel blocker presented a higher reduction in day-to-day variability as assessed using HBPM compared to that observed in patients who received olmesartan and the diuretic, despite similar reductions in the absolute home BP levels. In addition, a possible relationship was observed between the reduction in variability and an improvement in a marker of asymptomatic target organ damage, such as aortic rigidity, assessed by measuring carotid-femoral pulse wave velocity [51].

One of the physiopathological changes most closely related to increased BP variability is sympathetic hyperactivity. Accordingly, the results of a sub-analysis of the previously mentioned studies are also of interest. Based on the HONEST data, a higher relative reduction in heart rate was observed in HBPM readings in patients with higher baseline ambulatory systolic BP and heart rate. This tendency was clear in the patient subgroup with chronic kidney disease, in which sympathetic hyperactivity is usually greater. The authors of this study concluded that treatment with olmesartan may have an added beneficial effect on intrarenal circulation in patients with chronic kidney disease and the resulting sympathetic hyperactivity [52].

\section{LIMITATIONS}

Most of the studies on the effect of olmesartan and olmesartan-based treatments on variables related to ambulatory BP included in this review are open-label, non-comparative studies. These limitations are recognized in the original publications. Furthermore, the inclusion criteria of this review exclude trials designed the same as those mentioned carried out with other therapeutic alternatives. In this regard, there are studies on the effect of ambulatory BP, mostly with ABPM, with double and triple combinations based on different reninangiotensin system blockers [53-55] with results in line with those mentioned for olmesartan.

\section{CONCLUSIONS}

Assessing ambulatory BP, both for diagnosing as well as for monitoring patients with HTN, and improving the degree of overall HTN control are currently priorities in managing this disease. The results from the studies that have evaluated the effect of olmesartan-based treatments indicate that these have positive effects on the ambulatory BP prognostic indicators such as 24-h BP control, nighttime BP control, BP measured using self-measurement at home, morning surge, and BP variability measured using ABPM or HBPM. It would be desirable to observe whether these benefits translate to reductions in morbidity and mortality in patients with HTN.

\section{ACKNOWLEDGMENTS}

This supplement has been sponsored by Menarini. The named author meets the International Committee of Medical Journal Editors (ICMJE) criteria for authorship for this manuscript, takes responsibility for the integrity of the work as a whole, and has given final approval for the version to be published. 


\section{Conflict of interest. Manuel Gorostidi} declares honoraria for participation in scientific meetings funded by Daiichi-Sankyo, Lacer, Menarini, Novartis, and Pfizer.

Compliance with ethics guidelines. This article is based on previously conducted studies and does not involve any new studies of human or animal subjects performed by the author.

Open Access. This article is distributed under the terms of the Creative Commons Attribution Noncommercial License which permits any noncommercial use, distribution, and reproduction in any medium, provided the original author(s) and the source are credited.

\section{REFERENCES}

1. Mancia G, Fagard R, Narkiewicz K, et al. 2013 ESH/ ESC Guidelines for the management of arterial hypertension. The Task Force for the management of arterial hypertension of the European Society of Hypertension (ESH) and of the European Society of Cardiology (ESC). J Hypertens. 2013;31:1281-357.

2. James PA, Oparil S, Carter BL, et al. 2014 evidencebased guideline for the management of high blood pressure in adults: report from the panel members appointed to the Eighth Joint National Committee (JNC 8). JAMA. 2014;311:507-20.

3. Weber MA, Schiffrin EL, White WB, et al. Clinical practice guidelines for the management of hypertension in the community a statement by the American Society of Hypertension and the International Society of Hypertension. J Hypertens. 2014;32:3-15.

4. Banegas JR, Graciani A, de la Cruz-Troca JJ, et al. Achievement of cardiometabolic goals in aware hypertensive patients in Spain: a nationwide population-based study. Hypertension. 2012;60:898-905.

5. Thomopoulos C, Parati G, Zanchetti A. Effects of blood pressure lowering on outcome incidence in hypertension. 1. Overview, meta-analyses, and meta-regression analyses of randomized trials. J Hypertens. 2014;32:2285-95.

6. Parati G, Stergiou GS, Asmar R, et al. On behalf of the ESH Working Group on Blood Pressure Monitoring. European Society of Hypertension guidelines for blood pressure monitoring at home: a summary report of the Second International Consensus Conference on Home Blood Pressure Monitoring. J Hypertens. 2008;26:1505-26.

7. Pickering TG, Miller NH, Ogedegbe G, Krakoff LR, Artinian NT, Goff D. Call to action on use and reimbursement for home blood pressure monitoring: a joint scientific statement from the American Heart Association, American Society Of Hypertension, and Preventive Cardiovascular Nurses Association. Hypertension. 2008;52:10-29.

8. O'Brien E, Parati G, Stergiou G, et al, On behalf of the European Society of Hypertension Working Group on Blood Pressure Monitoring. European Society of Hypertension position paper on ambulatory blood pressure monitoring. J Hypertens. 2013;31:1731-68.

9. Ohkubo T, Imai Y, Tsuji I, et al. Home blood pressure measurement has a stronger predictive power for mortality than screening blood pressure measurement: a population-based observation in Ohasama. Japan J Hypertens. 1998;16:971-5.

10. Bobrie G, Chatellier G, Genes N, et al. Cardiovascular prognosis of 'masked hypertension' detected by blood pressure self-measurement in elderly treated hypertensive patients. JAMA. 2004;291:1342-9.

11. Sega R, Facchetti R, Bombelli M, et al. Prognostic value of ambulatory and home blood pressures compared with office blood pressure in the general population: follow-up results from the Pressioni Arteriose Monitorate e Loro Associazioni (PAMELA) study. Circulation. 2005;111:1777-83.

12. Niiranen TJ, Hänninen MR, Johansson J, Reunanen A, Jula AM. Home-measured blood pressure is a stronger predictor of cardiovascular risk than office blood pressure: the Finn-Home study. Hypertension. 2010;55:1346-51.

13. Stergiou GS, Siontis KC, Ioannidis JP. Home blood pressure as a cardiovascular outcome predictor: it's time to take this method seriously. Hypertension. 2010;55:1301-3.

14. Ward AM, Takahashi O, Stevens R, Heneghan C. Home measurement of blood pressure and cardiovascular disease: systematic review and meta-analysis of prospective studies. J Hypertens. 2012;30:449-56. 
15. Verdecchia P, Porcellati C, Schillaci G, et al. Ambulatory blood pressure. An independent predictor of prognosis in essential hypertension. Hypertension. 1994;24:793-801.

16. Staessen JA, Thijs L, Fagard R, et al. Predicting cardiovascular risk using conventional vs ambulatory blood pressure in older patients with systolic hypertension. Systolic Hypertension in Europe Trial Investigators. JAMA. 1999;282:539-46.

17. Clement DL, de Buyzere ML, de Bacquer DA, et al. Office versus Ambulatory Pressure Study Investigators. Prognostic value of ambulatory blood-pressure recordings in patients with treated hypertension. N Engl J Med. 2003;348:2407-15.

18. Kikuya M, Ohkubo T, Asayama K, et al. Ambulatory blood pressure and 10-year risk of cardiovascular and noncardiovascular mortality: the Ohasama study. Hypertension. 2005;45:240-5.

19. Dolan E, Stanton A, Thijs L, et al. Superiority of ambulatory over clinic blood pressure measurement in predicting mortality: the Dublin outcome study. Hypertension. 2005;46:156-61.

20. Hansen TW, Kikuya M, Thijs L, et al. IDACO Investigators. Prognostic superiority of daytime ambulatory over conventional blood pressure in four populations: a meta-analysis of 7,030 individuals. J Hypertens. 2007;25:1554-64.

21. De la Sierra A, Banegas JR, Segura J, Gorostidi M, Ruilope LM. On behalf of the CARDIORISC Event Investigators. Ambulatory blood pressure monitoring and development of cardiovascular events in high-risk patients included in the Spanish ABPM registry: the CARDIORISC Event study. J Hypertens. 2012;30:713-9.

22. National Institute for Health and Clinical Excellence (NICE). Hypertension. The clinical management of primary hypertension in adults. Clinical Guideline 127. 2011. Available at: www. nice.org.uk/guidance/CG127. Accessed 11 June 2015 .

23. Gorostidi M, Sobrino J, Segura J, et al. On behalf of the Spanish Society of Hypertension ABPM Registry investigators. Ambulatory blood pressure monitoring in hypertensive patients with high cardiovascular risk: a cross-sectional analysis of a 20,000-patient database in Spain. J Hypertens. 2007;25:977-84.

24. Gorostidi M, de la Sierra A, González-Albarrán O, et al. On behalf of the Spanish Society of Hypertension ABPM Registry investigators. Abnormalities in ambulatory blood pressure monitoring in hypertensive patients with diabetes. Hypertens Res. 2011;34:1185-9.
25. Gorostidi M, Sarafidis PA, de la Sierra A, et al. On behalf of the Spanish ABPM Registry. Differences between office and 24-hour blood pressure control in hypertensive patients with CKD: A 5,693-patient cross-sectional analysis from Spain. Am J Kidney Dis. 2013;62:285-94.

26. Izzo JL Jr, Chrysant SG, Kereiakes DJ, et al. 24-hour efficacy and safety of Triple-Combination Therapy With Olmesartan, Amlodipine, and Hydrochlorothiazide: the TRINITY ambulatory blood pressure substudy. J Clin Hypertens (Greenwich). 2011;13:873-80.

27. Weir MR, Hsueh WA, Nesbitt SD, et al. A titrate-togoal study of switching patients uncontrolled on antihypertensive monotherapy to fixed-dose combinations of amlodipine and olmesartan medoxomil \pm hydrochlorothiazide. J Clin Hypertens (Greenwich). 2011;13:404-12.

28. Ogihara T, Saruta T, Shimada K, Kuramoto K. A randomized, double blind, four-arm parallel-group study of the efficacy and safety of azelnidipine and olmesartan medoxomil combination therapy compared with each monotherapy in Japanese patients with essential hypertension: the REZALT study. Hypertens Res. 2009;32:1148-54.

29. Shimada K, Ogihara T, Saruta T, Kuramoto K, for the REZALT Study Group. Effects of combination olmesartan medoxomil plus azelnidipine versus monotherapy with either agent on 24-hour ambulatory blood pressure and pulse rate in Japanese patients with essential hypertension: additional results from the REZALT study. Clin Ther. 2010;32:861-81.

30. Punzi H, Neutel JM, Kereiakes DJ, et al. Efficacy of amlodipine and olmesartan medoxomil in patients with hypertension: the AZOR Trial Evaluating Blood Pressure Reductions and Control (AZTEC) study. Ther Adv Cardiovasc Dis. 2010;4:209-21.

31. Ram CV, Sachson $\mathrm{R}$, Littlejohn $\mathrm{T}$, et al. Management of hypertension in patients with diabetes using an amlodipine-, olmesartan medoxomil-, and hydrochlorothiazide-based titration regimen. Am J Cardiol. 2011;107:1346-52.

32. Zemmrich C, Lüders S, Gansz A, et al. Daytime systolic ambulatory blood pressure with a direct switch between candesartan monotherapy and the fixed-dose combination olmesartan/amlodipine in patients with uncontrolled essential hypertension (SEVICONTROL-1). J Clin Hypertens (Greenwich). 2013;15:815-9.

33. Bramlage P, Zemmrich C, Gansz A, et al. Daytime systolic ambulatory blood pressure with a two-step switch from candesartan to olmesartan 
monotherapy and the fixed-dose combination of olmesartan/amlodipine in patients with uncontrolled essential hypertension (SEVICONTROL-2). J Clin Hypertens (Greenwich). 2014;16:41-6.

34. Gorostidi M, de la Sierra A. Combination therapy in hypertension. Adv Ther. 2013;30:320-6.

35. Saito I, Kario K, Kushiro T, et al. Rationale, study design, baseline characteristics and blood pressure at 16 weeks in the HONEST Study. Hypertens Res. 2013;36:177-82.

36. Kario K, Saito I, Kushiro T, et al. Effect of the angiotensin II receptor antagonist olmesartan on morning home blood pressure in hypertension: HONEST study at 16 weeks. J Hum Hypertens. 2013;27:721-8.

37. Boggia J, Li Y, Thijs L, et al. International Database on Ambulatory blood pressure monitoring in relation to Cardiovascular Outcomes (IDACO) Investigators. Prognostic accuracy of day versus night ambulatory blood pressure: a cohort study. Lancet. 2007;370:1219-29.

38. De la Sierra A, Redon J, Banegas JR, et al. On behalf of the Spanish Society of Hypertension Ambulatory Blood Monitoring Registry Investigators. Prevalence and factors associated with circadian blood pressure patterns in hypertensive patients. Hypertension. 2009;53:466-72.

39. Hermida RC, Ayala DE, Mojón A, Fernández JR. Influence of circadian time of hypertension treatment on cardiovascular risk: result of the MAPEC study. Chronobiol Int. 2010;27:1629-51.

40. Rahman M, Greene T, Phillips RA, et al. A trial of 2 strategies to reduce nocturnal blood pressure in blacks with chronic kidney disease. Hypertension. 2013;61:82-8.

41. Smolensky MH, Hermida RC, Portaluppi F. Comparison of the efficacy of morning versus evening administration of olmesartan in uncomplicated essential hypertension. Chromobiol Int. 2007;24:171-81.

42. Tofé Povedano, García de la Villa B. 24-hour and night-time blood pressures in type 2 diabetic hypertensive patients following morning or evening administration of olmesartan. J Clin Hypertens (Greenwich). 2009;11:473-9.

43. Mori $\mathrm{H}$, Yamamoto $\mathrm{H}$, Ukai $\mathrm{H}$, et al. COMPATIBLE Study Group. Comparison of effects of angiotensin II receptor blocker on morning home blood pressure and cardiorenal protection between morning administration and evening administration in hypertensive patients: the COMPATIBLE study. Hypertens Res. 2013;36:202-7.

44. Sakai Y, Suzuki A, Mugishima K, et al. Comparison of once daily versus twice daily olmesartan in patients with chronic kidney disease. Int J Nephrol Renovasc Dis. 2013:11(6):223-7.

45. Jiang H, Ke YN, Sun NL, Wang JG, Hou MW, Zhu JR, On behalf of Olmesartan Medoxomil Clinical Collaborative Panel of EXPO Study. Using different methods to evaluate the efficacy of olmesartan medoxomil in Chinese patients with mild to moderate essential hypertension according to ambulatory blood pressure monitoring. Blood Press Monit. 2012;17:193-7.

46. Jiao Y, Ke Y, Sun N, Wang J, Deng W, Zhu J, on behalf of the Olmesartan Medoxomil Clinical Collaborative Panel of the EXPO Study. Reduction of the morning blood pressure surge treated with olmesartan in Chinese patients with mild to moderate essential hypertension-a multicenter, open-label, single treatment group clinical study. Eur Rev Med Pharmacol Sci. 2012;16:653-9.

47. Bilo G, Koch W, Hoshide S, Parati G. Efficacy of olmesartan/amlodipine combination therapy in reducing ambulatory blood pressure in moderateto-severe hypertensive patients not controlled by amlodipine alone. Hypertens Res. 2014;37:836-44.

48. Makani H, Bangalore S, Supariwala A, Romero J, Argulian E, Messerli FH. Antihypertensive efficacy of angiotensin receptor blockers as monotherapy as evaluated by ambulatory blood pressure monitoring: a meta-analysis. Eur Heart J. 2014;35:1732-42.

49. Stergiou GS, Parati G. How to best assess blood pressure? The ongoing debate on the clinical value of blood pressure average and variability. Hypertension. 2011;57:1041-2.

50. Parati G, Ochoa JE, Lombardi C, Bilo G. Assessment and management of blood-pressure variability. Nat Rev Cardiol. 2013;10:143-55.

51. Matsui Y, O'Rourke MF, Hoshide S, Ishikawa J, Shimada K, Kario K. Combined effect of angiotensin II receptor blocker and either a calcium channel blocker or diuretic on day-by-day variability of home blood pressure: the Japan Combined Treatment With Olmesartan and a Calcium-Channel Blocker Versus Olmesartan and Diuretics Randomized Efficacy Study. Hypertension. 2012;59:1132-8.

52. Kario K, Saito I, Kushiro T, et al. Enhanced blood pressure-lowering effect of olmesartan in hypertensive patients with chronic kidney diseaseassociated sympathetic hyperactivity: HONEST 
Study. J Clin Hypertens (Greenwich). 2013;15:555-61.

53. Parati G, Bilo G, Redon J, SURGE Steering Committee. The effects of telmisartan alone or with hydrochlorothiazide on morning and 24-h ambulatory BP control: results from a practicebased study (SURGE 2). Hypertens Res. 2013;36:322-7.

54. Lacourcière $\mathrm{Y}$, Crikelair $\mathrm{N}$, Glazer RD, Yen J, Calhoun DA. 24-Hour ambulatory blood pressure control with triple-therapy amlodipine, valsartan and hydrochlorothiazide in patients with moderate to severe hypertension. J Hum Hypertens. 2011;25:615-22.

55. Tóth $\mathrm{K}$, for the PIANIST Investigators. Antihypertensive efficacy of triple combination perindopril/indapamide plus amlodipine in highrisk hypertensives: results of the PIANIST study (Perindopril-Indapamide plus AmlodipiNe in high rISk hyperTensive patients). Am J Cardiovasc Drugs. 2014;14:137-45 (Erratum in Am J Cardiovasc Drugs. 2014;14:239). 